\title{
« Douleur, culture, migration, violence, torture »
}

\author{
V. Barfety-Servignat $\cdot$ E. Collin
}

(C) Lavoisier SAS 2020

« Depuis lors, à une heure incertaine, Cette souffrance lui revient,

Et si, pour l'écouter, il ne trouve personne,

Dans la poitrine, le cœur lui brûle. »

$$
\begin{array}{r}
\text { Primo Levi } \\
\text { Le Survivant (extrait) }
\end{array}
$$

Immigration, expatriation et exil sont tous trois des modalités de changement culturel et d'ébranlement identitaire possibles pour le sujet pouvant s'exprimer sur le registre de la douleur. Dans ce dossier « douleur, culture, migration, violence, torture ", nous avons souhaité aborder les questions de culture, de déracinement et de violences associées à la migration concernant les patients en situation d'exil que nous recevons dans nos consultations spécialisées en clinique de la douleur.

Ce sont des questions centrales, puisque selon le Comede, fin 2017 , la plupart des demandeurs d'asile ont subi des violences dans leur pays d'origine, pendant le parcours migratoire et/ou lors des premiers mois de leur arrivée en France : pour $81 \%$ d'entre eux, on relève des antécédents de violences (définition OMS), pour $21 \%$ des antécédents de torture (définition ONU) et pour $19 \%$ d'entre eux, des antécédents de violences liées au genre ${ }^{1}$. Entre 2004 et 2010, la prévalence des syndromes psychotraumatiques s'élevait à $112 \%$ dans la population ayant consulté un médecin dans les centres de santé du Comede ${ }^{2}$. On part de son pays pour fuir la violence, par rêve de pouvoir se construire ailleurs, mais les violences peuvent émailler le parcours et être souvent pré-

\footnotetext{
V. Barfety-Servignat $(\square)$

Consultation douleur et rhumatologie, clinique de rhumatologie, CHU de Lille, avenue du Professeur-Émile-Laine,

F-59000 Lille, France

e-mail : vbarfety@gmail.com

E. Collin $(\square)$

Consultation d'étude et de traitement de la douleur

Hôpital Avicenne,

125 , rue de Stalingrad,

F-93000 Bobigny, France

e-mail : elisabeth.collin2@aphp.fr
}

\footnotetext{
$\overline{{ }^{1} \text { https://www.comede.org/demandeurs-dasile/ }}$
}

sentes à l'arrivée. Vulnérabilité, précarité, morcellement, attentes de logement, de papier et finalement d'avenir s'accumulent.

La douleur, fenêtre sur l'intime, participe à l'unité du corps. Elle peut exprimer une lésion ou ses traces mais aussi l'épuisement, l'enchaînement des violences, l'incertitude. Elle peut freiner toute élaboration psychique, mais le trauma ancre la douleur. Lien secret à l'histoire de la personne, elle doit être identifiée à sa juste place. Là est la difficulté. En outre, la douleur s'exprime à partir du moment où elle peut être pensée et est souvent masquée par les autres problèmes sociosanitaires (hébergement [《esclavagisation »], « $115 »)$, administratifs (papiers...), souvenirs traumatiques... Ces contextes sont producteurs de nombreux troubles dans la sphère somatique, dont les douleurs, et pour lesquels le corps semble inscrire une véritable mémoire de ces ébranlements parfois très graves et très douloureux. Maladies, séquelles et psychotraumatismes sont alors les situations médicales et psychologiques qui se présentent dans les structures et qu'il nous faut prendre en compte. Et pour ces personnes, ces patients, le contexte d'accueil nécessite des conditions de consultation qui puissent accueillir la plainte somatique infiltrée de l'histoire et de l'ébranlement, qui prennent le temps de s'attacher aux silences et aux mots de ces hommes et de ces femmes qui ont survécu et qui ont besoin d'être respectés dans ce qu'ils vivent physiquement et psychiquement.

Quelle que soit notre place de soignant autour d'une personne venue de loin avec un parcours traumatique, l'apaisement est indissociable d'une prise en charge holistique. Il est souvent difficile lorsque la douleur représente un lien secret à l'histoire de la personne - où passé et présent sont douloureux et où l'avenir incertain. Il nécessite la construction d'un lien, là où tout est rompu, il implique de redonner existence au corps là où, paradoxalement, il est oublié. Respecter, accepter, sans jugement ni pitié. Le lieu du suivi est parfois difficile à établir, et les équipes spécialisées (« douleur », « psychotrauma », services sociaux, médiateurs en santé,

\footnotetext{
${ }^{2}$ Veïsse A, Wolmark L, Revault P (2012) Santé mentale des migrants/ étrangers : mieux caractériser pour mieux soigner. Bull Epidemiol hebdo 2-3-4:36-9
} 
etc.) doivent si possible avoir une unité de lieu et travailler en cohérence autour du patient.

Ces personnes ne croisent pas toujours les structures de la douleur, loin s'en faut. L'accès aux soins n'est pas si simple. Dans un monde où les mouvements migratoires s'intensifient, la réflexion sur la construction d'un parcours de soins est nécessaire. Ouvrir sa porte, comme le fait dans ce numéro Douleur et Analgésie, peut aider à trouver des pistes pour une prise en charge adaptée.
Ce numéro de Douleur et Analgésie s'est construit dans une période sanitaire complexe, et nous remercions les auteurs pour leur production dans un champ où la littérature est un perpétuel questionnement. À travers des mises au point, des études et cas cliniques, ce numéro tente d'apporter des pierres à l'édifice de cette réflexion sur culture, migration, violence, torture et douleur. 